\title{
Sexual Abuse Amongst Secondary School Students in Port Harcourt, South-South Nigeria: A Rising Public Health Menace, Factors and Implications
}

\section{Joyce Okagua* and Balafama A Alex- Hart}

Department of Paediatrics, University of Port Harcourt Teaching Hospital, Port Harcourt, Nigeria

*Corresponding Author: Joyce Okagua, Department of Paediatrics, University of Port Harcourt Teaching Hospital, Port Harcourt, Rivers State, Nigeria.

DOI: 10.31080/ASPE.2020.03.0224
Received: February 06, 2020;

Published: February 11, 2020

(C) All rights are reserved by Joyce Okagua

and Balafama A Alex- Hart.

\section{Abstract}

Background: Child sexual abuse has been implicated in most of adult psychopathologies including depression, post-traumatic stress disorders, eating disorders and even suicide. However, it remains a hidden truth due to stigmatization and cultural expectations in our environment.

Objective: To determine the prevalence of sexual abuse and determine the factors associated with sexual abuse amongst secondary school students in Port Harcourt, South-South Nigeria.

Method: This study was a cross sectional study amongst secondary school students conducted in Port Harcourt from September to December 2018. A structured, self-administered questionnaire was distributed to 1162 secondary school students from 6 public secondary schools selected through Multistage Sampling technique. Questions asked covered socio-demographics, knowledge on sexual abuse, exposure to different forms of sexual abuse, age at first abuse, gender of perpetrator and consequence of the abuse. Data was analyzed using SPSS version 21 .

Results: One thousand one hundred and sixty-two students were recruited in the study. There were 590 females and 572 males giving a male to female ratio of $1: 1.1$. They were aged $10-20$ years with a mean age of $14.8 \pm 2.1$ years. Overall, 422 ( $38.9 \%$ ) of the subjects had experienced at least one or more forms of sexual abuse whilst $710(61.1 \%)$ had never. Of these, $234(51.8 \%)$ were females whilst $218(48.2 \%)$ were males, however, this gender difference was not statistically significant $(\chi 2=0.3, p=0.588) .146(32.4 \%)$ of these abuses were by exposure to pornographic pictures and movies, $136(30.1 \%)$ were by using an object or his or her fingers into their anus or vagina, whilst 48 (10.6\%) was by forceful sexual intercourse with penetration. Majority (41.9\%) of the sexual abuse were first experienced between ages 8 - 12 years and dropped at ages 15 - 16 years. Three hundred and fifty-two (77.9\%) of the subjects were abused by male perpetrators whilst $100(22.1 \%)$ were by female perpetrators. This gender difference was statistically significant $((\chi 2=74.2, \mathrm{p}=0.000)$. Of these perpetrators, $61 \%$ were persons known to the subjects and only $(16 \%)$ were strangers. Conclusion: The prevalence of sexual abuse and forceful penetration of $38.9 \%$ and $10.6 \%$ respectively found in this study is high, with a changing pattern of an increasing male prevalence. Sexual education should be inculcated into the School Health Programme in the foundation school years with a mandatory reporting system in order to educate and protect these adolescents both in school and at home.

Keywords: Sexual Abuse; Secondary School; Factors; Southern Nigeria

\section{Introduction}

Child sexual abuse has been defined as the involvement in sexual activity that he or she does not fully comprehend and is unable to give informed consent to [1]. It includes acts, forceful or otherwise, of inappropriate sexual solicitation, genital touching or fondling, exposure of a child by an older person, intercourse through oral, anal or vaginal penetration and attempted intercourse [2]. Children may be sexually abused by both adults and other children (who are by virtue of their age or stage of development) in a position of responsibility, trust or power over the child victim [1-3].
The WHO estimated that about150 million girls experienced sexual violence with physical contact in 2002 [4]. Most perpetrators of sexual abuse are males and are often known to their victims [5]. While it is generally acknowledged that sexual abuse is pervasive in all countries and at all levels of society, available statistics concerning the prevalence of sexual abuse in children around the world in and in sub-Saharan Africa in particular are very limited [4-6].

United Nations International Children's Fund (UNICEF) reported in 2015 that one in four girls and one in ten boys in Nigeria had 
experienced sexual violence before the age of 18 [7]. According to a survey by Positive Action for Treatment Access, over 31.4 percent of girls said that their first sexual encounter had been rape or forced sex of some kind [8]. Globally, India has the world's largest number of child sexual abuse: For every 155th minute a child, less than 16 years is raped, for every 13th hour a child under 10 , and one in every 10 children sexually abused at any point of time [9]. However, a meta-analysis done in 2009 had showed that the highest prevalence was seen in Africa (34.4\%) [10,11] with Europe, America, and Asia with prevalence rates of $9.2 \%, 10.1 \%$, and $23.9 \%$, respectively [10]. In Nigeria, most studies have been done in different parts with varying methodology thus giving varying prevalent rates [12-16]. Most studies have reported a higher prevalence in girls than in boys with most sexual perpetrators (95\%) known to the child and even highly trusted by them. (relatives, neighbours, step- parents, highly trusted people) [4,13-15]. The trauma of sexual abuse leaves long term psychological and medical problems, some of which puts the adolescent at more risk for repeated sexual abuse.

It is therefore imperative to study these vulnerable group of children in order to provide initiatives and live saving skills with the schools as prime sites for dissemination of these solutions. The aim of this study is to determine and assess the factors associated with sexual abuse amongst secondary school students in Port Harcourt, South-South Nigeria.

\section{Methods and Material}

This study was a cross sectional study amongst secondary school students conducted in Port Harcourt from September to November 2018. A structured, self -administered questionnaire was distributed to 1,162 Secondary school students from 6 public secondary schools selected through Multistage Sampling technique amongst students aged $10-20$ years. The schools were first stratified into all boys, all girls and mixed schools, and six secondary schools ( 2 all girls, 2 all boys and 2 mixed) were selected by simple random sampling. The study was conducted in Port Harcourt city, Southern Nigeria over a period of ten weeks. It is an urban city, highly industrialized and oil and gas exploration is the mainstay of the economy.

Permission was obtained from the Rivers State Ministry of Education and from the Head teachers of the 6 selected schools and the parents or guardians and assent from the selected students. This study was carried out on school days as all schools were day schools and the subjects were self interviewed on relevant information. Information sought included socio-demographic status, exposure to any form of sexual abuse, age at first exposure, any history of repeated exposures, assailant's gender and relationship, any prior knowledge of sexual assault and any help sought after the assault. Students in the selected schools, who gave assent for the study, and whose parents or guardians gave consent, made up the study population.

\section{Ethical approval}

Ethics Committee of Rivers State University Teaching Hospital and the Administrative heads of the schools gave approval for the study.

\section{Consent}

Informed consent was obtained from the parents and assent from the students.

\section{Data analysis}

Data entry and analysis was done using SPSS software version 21.0 (IBM Corporation, Atlanta, GA, USA). Data analysis was by univariate and bivariate measures. Univariate analysis was based on frequency distribution of selected sociodemographic variables that are related to the study in the dataset. Bivariate analysis was employed to show the association between the variables including age, gender, parental living, and sexual abuse. Chi-square test was used to show this association, and in all cases, a probability value ( $p$ - value) of $<0.05$ was regarded as statistically significant.

\section{Results}

A total of 1,162 students were recruited in the study. There were $590(50.8 \%)$ females and $572(49.2 \%)$ males giving a male to female ratio of 1:1.1. They were aged between $10-20$ years with a mean age of $14.8 \pm 2.1$ years.

Table 1 shows the socio-demographic characteristics of the subjects. Majority (49.8\%) of the subjects were aged between 15 - 19 years, whilst $46.4 \%$ were aged 10 - 14 years and only $1.4 \%$ were aged 20 years. Of the subjects, 502 (43.2\%) of them lived with their parents whilst $660(56.8 \%)$ lived with other relatives (aunties, uncles, siblings and guardians). Majority of the students (59.4\%) were in senior secondary schools whilst $40.6 \%$ were in junior secondary school.

\section{Prevalence of sexual abuse}

Overall, 422 (38.9\%) of the subjects had experienced at least one or more forms of sexual assault whilst $710(61.1 \%)$ had never. Of those who had experienced these, 234 (51.8\%) were females whilst $218(48.2 \%)$ were males, as shown in figures 1 and 2 respectively. This gender difference was not statistically significant $(\chi 2=$ $0.3, \mathrm{p}=0.588$ ).

Of these perpetrators, 153 (33.8\%) were care givers/family relatives, 123 (27.2\%) were neighbours, 104 (23\%) were friends/ peers, whilst only $72(16 \%)$ were strangers. 
Sexual Abuse Amongst Secondary School Students in Port Harcourt, South-South Nigeria: A Rising Public Health Menace, Factors and Implications

\begin{tabular}{|l|c|}
\hline \multicolumn{1}{|c|}{ Variables } & $\mathrm{n}(\%)$ \\
\hline Age & $539(46.4)$ \\
\hline $10-14$ & $579(49.8)$ \\
$20+$ & $16(1.4)$ \\
Mean (SD) & $14.8 \pm 2.1$ \\
\hline Gender & \\
\hline Girl & $590(50.8)$ \\
Boy & $572(49.2)$ \\
\hline Living with & \\
\hline Parents & $502(43.2)$ \\
Step - mother & $22(1.9)$ \\
Step - father & $18(1.6)$ \\
Other relatives & $570(49.1)$ \\
\hline Class & \\
\hline JSS1 & $40(3.4)$ \\
JSS2 & $210(18.1)$ \\
JSS3 & $222(19.1)$ \\
SSS1 & $100(8.6)$ \\
SSS2 & $382(32.9)$ \\
SSS3 & $208(17.9)$ \\
\hline Total & $1,162(100)$ \\
\hline
\end{tabular}

Table 1: Socio-demographic characteristics of respondents.

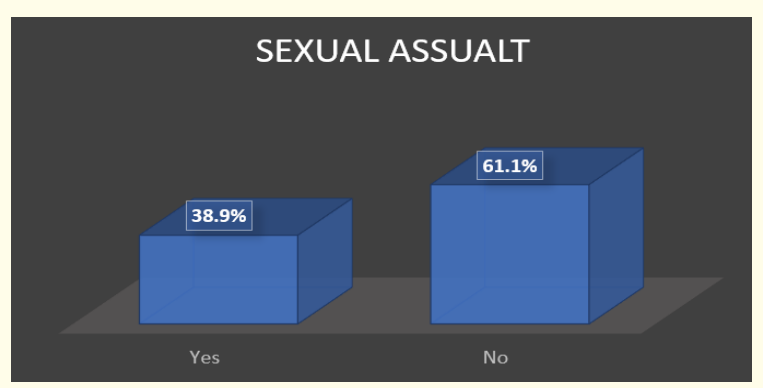

Figure 1: Prevalence of sexual abuse amongst the students.

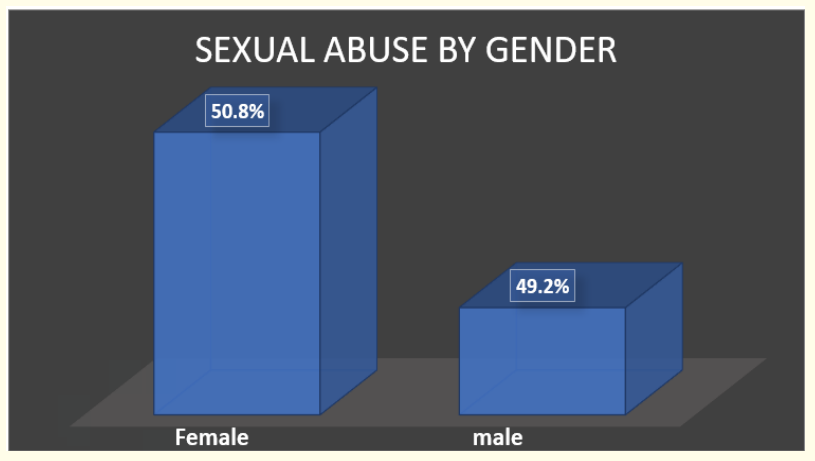

Figure 2: Gender prevalence of sexual abuse amongst the students.

\section{Mode of sexual assault}

Table 2 shows that 146 (32.4\%) of the sexual abuse were by exposure to pornographic pictures and movies, 136 (30.1\%) were by using an object or his or her fingers into their anus or vagina whilst $48(10.6 \%)$ was by forceful sexual intercourse with penetration.

\begin{tabular}{|l|c|}
\hline \multicolumn{1}{|c|}{ Variables } & $\mathrm{n}(\%)$ \\
\hline Sexual Abuse & $14(3.1)$ \\
\hline Look at his/her genitals & $20(4.4)$ \\
Undress and show him/her your genital & $8(1.7)$ \\
Watch him/her masturbate & $12(2.7)$ \\
$\begin{array}{l}\text { Undress with another child and fondle each other } \\
\text { in front of him/her }\end{array}$ & $10(2.2)$ \\
$\begin{array}{l}\text { Be fondled } \\
\text { Fondle him/her }\end{array}$ & $24(5.3)$ \\
$\begin{array}{l}\text { Look at pornographic pictures, drawing, films, } \\
\text { videotapes or magazines }\end{array}$ & $146(32.4)$ \\
$\begin{array}{l}\text { Be naked and to expose your genitals for picture } \\
\text { taking or filming }\end{array}$ & $34(7.5)$ \\
$\begin{array}{l}\text { Submit to full sexual intercourse with penetration } \\
\text { of the vaginal, anus }\end{array}$ & $48(10.6)$ \\
$\begin{array}{l}\text { Submit to having his/her fingers or an object intro- } \\
\text { duced into your body }\end{array}$ & $136(30.1)$ \\
\hline Total & $452(100)$ \\
\hline
\end{tabular}

Table 2: Mode of Sexual Abuse experienced by the study subjects.

Age at first sexual abuse and number of times abused

Of the students who experienced one or more forms of sexual abuse $86(19 \%)$ occurred first between the ages of $6-7$ years and gradually increased to $96(21.3 \%)$ at $11-12$ years then gradually decreased to 86 (19\%) at 15 - 16 years as shown in table 3.

\begin{tabular}{|l|l|}
\hline \multicolumn{1}{|c|}{ Respondent age (years) } & \multicolumn{1}{c|}{ n (\%) } \\
\hline $6-7$ & $86(19.0)$ \\
$8-10$ & $93(20.6)$ \\
$11-12$ & $96(21.3)$ \\
$13-14$ & $91(20.1)$ \\
$15-16$ & $86(19.0)$ \\
\hline Total & $452(100)$ \\
\hline
\end{tabular}

Table 3: Age at first sexual abuse of the subjects.

Of the subjects abused, majority of them 208 (46\%) were abused once, $200(44.3 \%)$ were abused more than once whilst 44 (9.7\%) were still being abused.

\section{Discussion}

In the present study, the overall prevalence of Sexual abuse was $38.9 \%$. This prevalence rate is similar to the $35.1 \%$ and $36 \%$ reported by Meichium., et al. [17] and Ajuwon., et al. [18] amongst Swiss and Nigerian adolescents respectively. However, this prevalence rate is higher than the $25.7 \%$ reported by David., et al. [19] 
amongst adolescents in a community in Lagos, South West Nigeria and the $10.2 \%$ reported by Chinawa., et al. [20] in South East Nigeria. Different methodology between the different studies may be responsible for the varying prevalence rates. Adolescents are likely to shy away from disclosure if information on sexual abuse is sought through an open interviewer administered survey. Also, it is important to note that variations in adolescent sexual abuse across geographical areas could either reflect true differences in incidence or be affected by how disclosure and reporting of cases are perceived in different cultures. Not withstanding, the reasons for non-reporting are complex and multifaceted [21]. These reasons may include factors such as the age of the abused child, the relationship between the perpetrator and the abused, and the likely consequences of the disclosure [22].

In this study, there were different forms of sexual assault with a higher prevalence of the subjects (32.4\%) haven been exposed to different forms of pornographic images and videos, whilst $10.6 \%$ were involved in forceful sexual intercourse with penetration. Similar findings have been reported by Meichum., et al. [17] and Anderson., et al. [23] amongst Swiss and South African pupils and Manyike., et al. [12] amongst adolescents in North East Nigeria. It is important to point out here the impact of pornography as a form of adolescent sexual abuse in this study. This is worrisome and may likely increase in the future as most of these images were aided and circulated to these young ones via different social media platforms and on the phones of the perpetrators in an unsuspecting manner. There are lots of studies about the effects of pornography on adolescents. There have been studies that seem to demonstrate arousal of perpetrators from viewing child pornography, particularly pedophile. It is not known if pornography makes them act on their arousal, but it seems to be part of the constellation about what causes them to abuse [24]. It's also found that viewing violent or sexual materials can affect attitudes involving adult rape. There is also a link between viewing violent pornography and repeat abuse by perpetrators, however the causation between the two is not known [24].

Similarly, reported incidence of rape in this study of $10.6 \%$ is similar to the previous findings of Ajuwon., et al. [18] in which 9\% reported rape. However, Achunike and Kitause [25] and Folayan., et al. [26] have expressed the epidemic nature of sexual abuse most especially rape among Nigerian young girls.

The findings of this study showed that $51.8 \%$ of the victims of sexual assault were females. This finding has again shown the high incidence of the occurrence of sexual abuse among adolescent girls. Many studies in Nigeria have reported a higher incidence of sexual abuse among adolescent girls [15,26-30]. compared to other age groups, and this has been attributed to their developmental stage. The findings also indicated that sexual abuse of adolescent girls is increasing among this population. In other countries, the trend of increasing rate of sexual abuse amongst adolescent girls has also been documented [31,32].

Similarly, reported incidence of rape in this study of $10.6 \%$ is also similar to the findings of Ajuwon., et al. [18] in which 9\% reported rape. However, Achunike and Kitause [25] and Folayan., et al. [26] have also expressed the epidemic nature of sexual abuse most especially rape among Nigerian young girls.

It is worrisome to note that the proportion of males sexually abused of $48.2 \%$ obtained in the present study is high, raising concerns about an almost proportional increase of male sexual abuse amongst adolescents in our environment. It therefore, highlights the existence of male sexual abuse in our communities which has hitherto been considered to occur mainly in developed countries. Thus, sexual abuse of boys may not be uncommon, but perhaps under recognized, under surveyed and therefore under reported. Moreover, most studies have concentrated on adolescent females without exploring these assaults on the males. A report by Ajuwon., et al. [18] amongst adolescents in North East Nigeria revealed more males than females reported sexual coercion. One possible explanation given was the religious context in which the survey was conducted, as in many parts of northern Nigeria women are kept in purdah, i.e. exclusion and when it is absolutely necessary for them to leave the home such as visiting a health facility or attend school they put on a veil and are not expected to have any direct contact with males. It therefore becomes worrisome that in our environment where the present study was conducted, both males and females are getting exposed to almost a similar risk without any protective factors. A scenario which over time if not curbed, could put more and more adolescents at a constant risk of sexual abuse.

In this study, sexual abuse was reported to have occurred as early as 6 years with a steady increase in incidence and peaking at 12 years with $21.3 \%$. This is similar to reports by Manyike., et al. [12] who reported more sexual for those above 12 years and least between 7 - 12 years. Hassan., et al. reported that [15] 61.8\% of the cases of sexual assault seen in a tertiary hospital in Sokoto, Northern Nigeria were amongst children less than 12 years. Other researchers have reported similar findings with children aged between 6-18 years more likely to suffer one or more forms of sexual assault $[34,35]$.

The report in this study and other reports by different researchers $[12,15,36]$ has become worrisome as most of these abuses occur very early in the lives of these young ones and especially as majority $(60 \%)$ of these perpetrators were persons familiar with the subjects and probably put under their care for supervision and protection. It is quite disturbing that most children were assaulted by well known persons trusted by both the children and their parents. 
All parents, therefore, need to be mindful of this risk when leaving their children alone with anyone, however, well known or trusted the individual might seem. Perpetrators that have been identified were in those homes were sophisticated monitoring devices were put in place at home, however, how many parents can afford such devices at home. Thus, most of these abuses may continue to go unnoticed if parents don't put in strong measures to monitor care givers.

The findings on more male perpetrators of sexual abuse as reported in this study supports the reports of by other researchers globally [12,14,15,32]. Ozbaran., et al. [33] Daru., et al. [23] and Manyike., et al. [12] that sexual violence is more likely to be perpetrated by peers, boyfriends, acquaintances, neighbours, or relatives, whilst Ogunfowokan., et al. [34] reported that male adolescents lone or gang raped their female sexual partners who were mostly adolescent girls.

\section{Conclusion}

The prevalence of sexual abuse of $38.9 \%$ found in this study is high and is increasing with a changing pattern. Males are increasingly been assaulted, but female victims are still in the majority. Adolescents remain a highly vulnerable group for sexual abuse with unsuspecting perpetrators. Therefore, strong legislations should be put in place to protect these vulnerable ones.

\section{Competing Interests}

The authors declare no competing interests.

\section{Bibliography}

1. Preventing child maltreatment: A guide to taking action and generating evidence. Geneva: World Health Organization 2006

2. Child sexual abuse. "Guidelines for medico-legal care of victims of sexual violence". Geneva: World Health Organization (2003): 75-92.

3. Finkelhor D. "The international epidemiology of child sexual abuse". Child Abuse and Neglect 18 (1994): 409-417.

4. Global estimates of health consequences due to violence against children. Background paper to the UN Secretary General's study on violence against children. Switzerland: World Health Organization 2006.

5. Terry KJ and Lalor K. "Child sexual abuse in sub-Saharan Africa: A literature review". Child Abuse and Neglect 28 (2004): 439-460.

6. Violence against women: A priority health issue. Geneva: World Health Organisation (1997): 1-12.

7. "Release of the findings of the Nigeria Violence Against Children Survey". UNICEF Nigeria (2015).

8. Is'haq Modibbo Kawu. "Nigeria's troubling epidemic of rapes". Vanguard (2013).
9. Childline organisation. Childline 1098 service.

10. Wihbey J. "Global prevalence of child sexual abuse". Journalist Resource.

11. Behere PB and Mulmule AN. "Sexual abuse in an 8-year-old child: Where do we stand legally?". Indian Journal of Psychological Medicine 35 (2013): 203-205.

12. Manyike PC., et al. "Child sexual abuse among adolescents in southeast Nigeria: A concealed public health behavioral issue". Pakistan Journal of Medical Sciences 31 (2015): 827-832.

13. Ezechi OC., et al. "Trends and patterns of sexual assaults in Lagos south-western Nigeria". Pan African Medical Journal 24 (2016): 261.

14. Bugaje MA., et al. "Child sexual abuse in Zaria, North-Western Nigeria”. Nigerian Journal of Paediatrics 39 (2012): 110-114.

15. Hassan M., et al. "Prevalence and pattern of sexual assault in Usmanu Danfodiyo University Teaching Hospital, Sokoto, Nigeria". Pan African Medical Journal 24 (2016): 332.

16. Akinlusi FM., et al. "Sexual assault in Lagos, Nigeria: a five-year retrospective review". BMC Women's Health 14 (2014):115.

17. Meichun M., et al. "Child Sexual Abuse Revisited: A PopulationBased Cross-Sectional Study Among Swiss Adolescents". Journal of Adolescent Health 54 (2014): 304-311.

18. Ajuwon AJ., et al. "Sexual behavior and experience of sexual coercion among secondary school students in three states in North Eastern Nigeria". BMC Public Health 6 (2006): 310.

19. David N., et al. "Child sexual abuse and disclosure in South Western Nigeria: a community based study". African Health Sciences 18 (2018): 199-208.

20. Chinawa JM., et al. "Prevalence and pattern of child abuse and associated factors in four secondary institutions in Enugu, Southeast Nigeria". European Journal of Pediatrics 173 (2013): 451-456.

21. Tallon J. Child sexual abuse: A review of the literature.

22. Jones LM., et al. "Why is sexual abuse declining? A survey of state child protection administrators". Child Abuse and Neglect 25 (2000): 1139-1158.

23. Anderson N., et al. "National cross sectional study of views on sexual violence and risk of HIV infection and AIDS among South African pupils". British Medical Journal 329 (2004): 7472-7952.

24. Childhood Sexual Abuse-Counseling Services- Obtainable.

25. Achunike HC and Kitause R. "Rape epidemic in Nigeria: Cases, causes, consequences and responses to the pandemic". International Journal of Research in Applied, Natural and Social Sciences 2 (2014): 31-44. 
26. Fawole OI., et al. "Violence and HIV/AIDS prevention among female out-of-school youths in Southwestern Nigeria: Lessons learnt from interventions targeted at hawkers and apprentices". African Journal of Medicine and Medical Sciences 33 (2004): 347-353.

27. Abasiattai AM., et al. "Reasons for gynaecological consultations in children in Calabar, South Eastern Nigeria". Tropical Doctor 37 (2007): 90-92.

28. Ekabua JE., et al. "Risk factors associated with sexual assault in Calabar, South Eastern Nigeria”. Nigerian Journal of Medicine 15 (2006): 406-408.

29. John C., et al. "Non-consensual sexual relationship and prevalence of HIV infection in adolescent in Jos, Nigeria". Nigerian Medical Journal 53 (2012): 210-212.

30. Daru PH., et al. "Analysis of cases of rape as seen at the Jos University Teaching Hospital, Jos, North Central Nigeria”. Nigerian Journal of Clinical Practice 14 (2011): 47-51.

31. DeSouza ER and Ribeiro J. "Bullying and sexual harassment among Brazilian high school students". Journal of Interpersonal Violence 20 (2005): 1018-1038.

32. Wagman J., et al. "Experiences of sexual coercion among adolescent women: Qualitative findings from Rakai district, Uganda". Journal of Interpersonal Violence 24 (2009): 2073-2095.

33. Ozbaran B., et al. "Social and emotional outcomes of child sexual abuse: A clinical sample in Turkey". Journal of Interpersonal Violence 24 (2009): 1478-1493.

34. Ogunfowokan AA., et al. "Correlates of self-report of rape among male school adolescents in Ile-Ife, Nigeria". Journal of Interpersonal Violence 31 (2016): 555-571.

35. Micaela C., et al. "Adolescents who experienced sexual abuse: fears, needs and impediments to disclosure". Child Abuse and Neglect 28 (2004): 1035-1048.

36. Olusanyan 0., et al. "The pattern of rape in Benin-City, Nigeria". Tropical and Geographical Medicine 38 (1986): 215-220.

\section{Assets from publication with us}

- Prompt Acknowledgement after receiving the article

- Thorough Double blinded peer review

- Rapid Publication

- Issue of Publication Certificate

- High visibility of your Published work

Website: $\underline{w w w . a c t a s c i e n t i f i c . c o m / ~}$

Submit Article: www.actascientific.com/submission.php

Email us: editor@actascientific.com

Contact us: +919182824667 